University of Minnesota Morris Digital Well

University of Minnesota Morris Digital Well

2-29-2016

\title{
Caste-Ethnic Disparity in Vaccine Use Among 0- to 5-Year-Old Children in Nepal: A Decomposition Analysis
}

\author{
Satis Devkota \\ University of Minnesota - Morris, sdevkota@morris.umn.edu \\ Christopher Butler \\ University of Minnesota - Morris
}

Follow this and additional works at: https://digitalcommons.morris.umn.edu/economics

Part of the Health Economics Commons, Medicine and Health Commons, and the Public Health Commons

\section{Recommended Citation}

Devkota, S., Butler, C. Caste-ethnic disparity in vaccine use among 0- to 5-year-old children in Nepal: a decomposition analysis. Int J Public Health 61, 693-699 (2016). https://doi.org/10.1007/ s00038-016-0789-9

This Article is brought to you for free and open access by the Faculty and Staff Scholarship at University of Minnesota Morris Digital Well. It has been accepted for inclusion in Economics \& Management Publications by an authorized administrator of University of Minnesota Morris Digital Well. For more information, please contact skulann@morris.umn.edu. 


\title{
Caste-ethnic disparity in vaccine use among 0- to 5-year-old children in Nepal: a decomposition analysis
}

\author{
Satis Devkota $\cdot$ Christopher Butler
}

Received: 6 March 2015/Revised: 13 September 2015/ Accepted: 12 January 2016/Published online: 29 February 2016

(C) Swiss School of Public Health (SSPH+) 2016

\begin{abstract}
Objectives To examine what factors, if any, could account for caste/ethnic disparities in vaccine utilization between upper caste and indigenous, and upper caste and low caste (Dalit) groups in Nepal.

Methods Using the Institute of Medicine (IOM) approach to calculate disparity, we estimate the disparity between upper caste and indigenous, and between upper caste and Dalit 0- to 5-year-old children in Nepal. Then we use Fairlie's non-linear regression-based decomposition technique to account for those disparities in immunization.

Results Using nationally representative data (the Nepal Living Standard Survey II and III), we construct a pooled cross-sectional series and calculate the disparity between upper caste and indigenous (8.047 \%), and between upper caste and Dalit $(7.215 \%)$. Both of these comparisons are significant at less than $1 \%$ significance level. Decomposition results show that a major portion of the disparity can be attributed to the difference in access to immunization services, followed by differences in household income and parental education.

Conclusions Nepal's national vaccine programs should increase focus on reaching geographically distant
\end{abstract}

Electronic supplementary material The online version of this article (doi:10.1007/s00038-016-0789-9) contains supplementary material, which is available to authorized users.

\footnotetext{
S. Devkota

Discipline of Economics and Management, Division of Social

Science, University of Minnesota, Morris, USA

e-mail: sdevkota@morris.umn.edu

C. Butler $(\bowtie)$

Department of Sociology, Division of Social Science, University

of Minnesota, Morris, USA

e-mail: cbutler@morris.umn.edu
}

populations, and continue to develop vaccination-related education efforts.

Keywords Vaccines - Immunization - Nepal ·

Disparities - Access to health facility $\cdot$ Caste ethnicity

\section{Introduction}

The United Nations' Millennium Development Goal 4 addresses child mortality as a major indicator of health and development, revealing much about a nation's health services and related social and economic factors. Currently, an estimated 8.1 million children die each year before age five, and approximately $99 \%$ of these childhood deaths occur in low-income and middle-income countries (CDC 2011).

Expanded vaccination coverage has been one of the most cost-effective ways to contain and lower the number of child deaths annually (WHO and UNICEF 2005). The cost for the basic six childhood vaccines is estimated to be less than one dollar (Gauri and Khaleghian 2002). With the realization of those benefits, the World Health Organization initiated its extended program on immunization (EPI) in 1974, which quickly gained acceptance in public health programs around the world.

In the first decade of the twenty-first century, an estimated 2.5 million child deaths were prevented each year through the use of measles, polio, and diphtheria-tetanuspertussis vaccine. Expanded coverage with the measles vaccine resulted in a $78 \%$ decline in measles mortality from 2000 to 2008, averting an estimated 12.7 million deaths worldwide (Centers for Disease Control 2011). Polio cases have decreased by over $99 \%$ since 1988, from an estimated 350,000 cases then, to 416 reported cases in 2013 (WHO 2014). 
Vaccines not only save lives, but also make ancillary long-term contributions to a nation's robustness. Improved health through vaccines contributes to economic growth in four ways: (1) they reduce production losses caused by worker illness; (2) they improve utilization of natural resources; (3) they increase the child enrollment numbers in schools; and (4) they liberate resources for other needs (household and national) that would otherwise be spent on treating illness (WDR 1993).

Nepal initiated an immunization program in 1977 after realizing the success of its pilot smallpox vaccination program, launched in 1967 (Acharya 2000). In 1979, Nepal piloted the expanded program on immunization (EPI) in three districts (Bara, Kaski, and Bhaktapur) to control vaccine preventable diseases (VPDs) with two antigens (BCG and DPT). By 1989 that program had been expanded to six antigens available in all 75 districts in the country. Presently, Nepal's national immunization program (NIP) provides the recommended antigens for seven VPDs: DPT (diphtheria), pertussis (whooping cough), tetanus, polio, Hepatitis B, BCG (tuberculosis), measles.

The Nepali government provides basic health services through 89 hospitals, 186 primary healthcare centers (PHC), 697 health posts (HP), and 3429 sub-health posts (SHP). The NIP operates about 15,000 immunization static, outreach, or mobile clinics per month (MOH [Nepal] 2007). Due to this work, Nepal has had remarkable success in improving under-five and infant mortality. However, neonatal mortality has been stagnant at 33/1000 live births since 2006, and accounts for $54 \%$ of under-five mortality. A majority of neonatal deaths caused by infection can be prevented with the appropriate vaccine program. But even with the full effort of the government and multilateral donors, utilization of vaccines in Nepal hovers around $87 \%$ and the immunization rate varies across the different caste-ethnic groups.

This last point is particularly important because Nepal is still regrouping from the strife of a decade-long conflict with Maoist rebels who built up considerable support by rallying low caste and indigenous groups on the basis of historical discriminations that today manifest as lived inequality. Understanding these disparities (such as vaccination rates) and addressing them with better-informed policy (as we propose to do) can not only improve public health, but also contribute to longer-term concerns about peace and stability in Nepal. Thus, we want to explore the factors that influence the utilization of vaccine for under-five children in Nepal. And because of the historical inequalities that persist along caste/ethnic lines (Pandey et al. 2013), we believe this is an appropriate starting distinction for our study. Accordingly, we set out guided by two questions: (1) is there a disparity in vaccine utilization based on caste or ethnicity, and (2) if yes, what factors contribute to that disparity?

\section{Methods}

Data and sample

We use the two rounds of the Nepal Living Standard Survey (NLSS II and III) and construct a pooled crosssectional series of individual and household level characteristics. The NLSS is a nationally representative survey of the Nepalese civilian non-institutionalized population. It compiles data on many dimensions of household well-being including consumption, income, savings, employment, health, immunization, education, fertility, nutrition, housing, and migration.

Dependent and independent variables

Our dependent variable $\left(Y_{i}\right)$ of interest is a child's immunization against seven fatal diseases. A child who received three DPT vaccines, three polio vaccines, three Hepatitis B vaccines, a BCG vaccine and a measles vaccine is regarded as 'fully immunized' $\left(Y_{i}=1\right)$. In contrast, a child who received any of these vaccines but not all of them is defined as 'partially immunized' $\left(Y_{i}=0\right)$. Thus, our dependent variable is binary and takes the values 0 and 1 .

We estimate the vaccine demand model, using the conceptual framework of Abebaw (2014), as drawn from Grossman (1972), which was applied in an Ethiopian context, one of the least developed countries in the world. Even though in most developing countries the actual immunization uptake (demand) depends on a parent's comparison of perceived cost and benefits of immunization (Abebaw 2014), in Nepal this factor should not matter as immunization services are freely available through the country's public health system. However, there are opportunity costs associated with the vaccination process. These include travel cost, potential income forgone during travel, and the waiting times for vaccination (Pande and Yazbeck 2003). On the other hand, the health benefits of immunization are widely documented in the biomedical literature.

Immunization is also determined by a host of non-price related factors (Borooah 2004; Kiros and White 2004; Lee 2005; Pande 2003). These include socio-economic factors such as household income, parental education, access to media and information, geographic location factors such as rural v. urban and the ecological zones (e.g., mountains v. plains) of child's household, distance to the nearest health facility, and various demographic factors such as age, sex, caste and ethnicity. Because we are studying the causes of caste/ethnic disparities (not the disparity over the time period) using pooled cross-sectional data, we control for time heterogeneity by introducing a time dummy. For this study, we classify age and sex as a need-related-variable 
and the other independent variables as non-need-related variables. This classification is used later to build the IOM definition of disparity in the utilization of vaccine in Nepal.

\section{Estimation of vaccine demand function}

As the dependent variable takes the binary values ( 1 = fully immunized; $0=$ not fully immunized), we can use the linear probability model (LPM) or a logit/probit model to estimate the vaccine demand function. Because the estimated probabilities using LPM for the demand for vaccine violates the assumption: $0 \leq P(Y \mid X=1) \leq 1$, we remain with the probit model. The probit model can be specified as follows:

$P\left(Y_{i}=1\right)=\phi\left(\alpha+X_{i j} \beta_{j}+\mu_{d}+\varepsilon_{i}\right)$,

where $Y_{i}$ is a binary variable showing the immunization status of child; $i, X_{i}$ is a set of explanatory variables described in the previous section, and $\mu_{d}$ is the time fixed effect unique to a particular year that captures the timeinvariant differences across the survey years. $\alpha$ and $\beta_{j}$ are regression parameters to be estimated. Finally, $\varepsilon_{i}$ is the error term that captures the impact of all other unobserved variables that vary across individuals, villages, and districts. $\phi$ is the standard normal cumulative distribution.

One of the explanatory variables in Eq. (1) is access abbreviated as ACS and hereafter a continuous variable measured in hours. Even though the distance measured in terms of kilometers or miles is the standard measures, because that is not reported in NLSS II, we use access to measure the time in hours for an individual to reach the nearest health facility from his or her home to the nearest health facility. Even though this variable is endogenous (Kumar et al. 2014) for two reasons, we use probit for the estimation (for details see Wagstaff et al. 2003).

\section{Disparity and decomposition}

For this study we consider the children aged between $0-5$ years. After deleting the missing information about the dependent variable, we have a sample of 6627 . We divided the sample $(N=6,627)$ into three groups based on caste and ethnicity.

We begin our study by examining unadjusted estimates of vaccine use for each group (Table 1). We then examine the caste/ethnic disparities in vaccine use, applying the IOM definition of disparity (IOM 2002): the difference in treatment or access not justified by the differences in health status or preferences of the groups (as qtd. in McGuire et al. 2006). Finally, we employ non-linear regressionbased decomposition methods (Blinder 1973; Fairlie 1999, 2005; and Oaxaca 1973) to explain the factors contributing to IOM disparity. For implementing the IOM definition of disparity, we use the following four-step method for calculating disparity as described by McGuire et al. (2006) and Cook et al. (2007).

1. We fit the probit regressions stated in Eq. (1) to each group.

2. We transform the distribution of need-related variables for groups II and III to be the same as the distribution among group I (upper caste), while leaving the nonneed-related variables unchanged. A "rank-and-replace" algorithm is used to make these transformations (McGuire et al. 2006 and Cook et al. 2007), thereby replicating the entire shape of the Group I's needrelated distribution.

3. We use the fitted probit regressions to calculate predicted values for use for each group, conditional on their transformed values for need-related variables, and their actual values for non-need-related variables defined above.

4. We average these predictions by group, and calculate a disparity as the difference between the hypothetical value for the indigenous and Dalit groups and the average value for the upper caste group.

After estimating these disparities, we use Fairlie's nonlinear regression decomposition (RD) method to differentiate between the portions of the IOM disparity attributable to differences in the measured characteristics of the two groups being compared (e.g., due to differences in parental education or distance to the nearest health care facility), and the portion attributable to difference in the "effects" of those characteristics as measured by their regression coefficients in the models estimated for each subpopulation. Details of the decomposition are provided in Appendix 1.

\section{Results}

Table 2 reports the population characteristics of upper caste, indigenous, and Dalit children aged $0-5$ years in a pooled cross-sectional sample drawn from NLSS II and III, and reveals the differences across groups. The NLSS II and III were conducted in 2003/2004 and 2010/2011, respectively.

Initially, we see the average rate of utilization of vaccine is $70.5 \%$ in upper caste, almost $7 \%$ higher than both the indigenous and Dalit groups. Those differences are statistically significant at less than $1 \%$ significant level. Several other notable differences among groups can be observed in Table 2. The average income (in natural $\log$ ) for upper caste is 11.598 , which is higher than for indigenous and Dalit groups. The differences in income in both cases are significant at less than $1 \%$ significant level. Even though a 
Table 1 Study groups

\begin{tabular}{lll}
\hline & Description of population & Number of children \\
\hline I. Upper caste & Brahmin, Chhetri, Newar, and Madwari; historically privileged groups in Hindu hierarchy & 1901 \\
II. Indigenous & Fifty-five indigenous groups in Nepal; excluded from Hindu hierarchy (NEFIN 2015) & 3088 \\
III. Dalit & $\begin{array}{l}\text { The low caste or untouchable classes, historically subject } \\
\text { to discrimination that have resulted in present-day inequalities }\end{array}$ & 1638 \\
\hline
\end{tabular}

large number of parents in all caste/ethnic groups are illiterate in Nepal, the parental education measured in terms of highest years of schooling completed by either of their parents is significantly higher for the upper caste. However, when looking at time to nearest health facility, upper caste families have further to travel than indigenous and Dalit families. When comparing urban and rural residency, $23.5 \%$ of upper caste children live in cities compared to just 19 and $17 \%$ of indigenous and Dalit children, respectively. The average family size in the upper caste is 6.245 , which is almost one less person per family than the other groups. That difference is also significant at less than $1 \%$ significance level.

Table 3 reports first step in revealing of utilization of vaccines, classified by caste/ethnic group in Nepal. The second column of the Table 3 reports the percentage of children in each group who are fully immunized. Based on that unadjusted measure of utilization, the differences in vaccine use between the upper caste and indigenous is $7.022 \%$ and between the upper caste and Dalit is $6.452 \%$. Both of these figures are significant to less than $1 \%$ significance level.

The differences reported in Table 3 are the first step in revealing the disparities in utilization of vaccines between the upper caste and the two subpopulations. Obviously, a question might be what are those disparities and how are those disparities different from differences? Table 4 answers those questions using the IOM definition of disparity (Institute of Medicine 2002). Supplemental digital content for probit regressions used to derive the results in Table 4 are reported in Appendix 1.

The IOM disparity in utilization of vaccines (reported in Table 4) is slightly higher between the indigenous and upper caste, and higher between Dalit and upper caste when compared with the simple differences in utilization reported in Table 3 above. The first panel of Table 4 reports the predicted percentage of vaccine utilization separately for each of our study groups. The predicted percentage of utilization of vaccine for the upper caste is $70.622 \%$. When assigned the need-related characteristics of the upper caste, the predicted percentage of vaccine utilization is $62.575 \%$ for the indigenous and $63.407 \%$ for Dalit. Thus, the IOM disparity between upper caste and indigenous is $8.047 \%$ (70.622-62.575), and $7.215 \%$ between upper caste and Dalit (70.622-63.407).

So, what underlying factors might explain these patterns of utilizations? We answer this question using a non-linear regression-based decomposition technique discussed in the methods section. Table 5 reports the decomposition results for the indigenous and Dalit groups. The total IOM disparity for each group is reported in the first row of the table. The next two rows decompose the disparity into two

Table 2 Characteristics of children aged 0-5 years in Nepal

\begin{tabular}{|c|c|c|c|c|}
\hline Variables list & Description of variables & Upper caste & Indigenous group & Dalit \\
\hline p_use: & Dependent variable. The probability of vaccine use & 0.705 & $0.637 * * *$ & $0.638 * * *$ \\
\hline ln_inc: & Natural logarithm of household income & 11.598 & $11.389 * * *$ & $11.215^{* * * *}$ \\
\hline e_par: & Parental education & 0.216 & $0.103 * * *$ & $0.122 * * *$ \\
\hline dist: & Measured in terms of travel time to the nearest health center in hours & 3.825 & $2.131 * * *$ & $2.402 * * *$ \\
\hline ur_ru: & Urban versus rural location of household & 0.235 & $0.198 * * *$ & $0.178 * * *$ \\
\hline age: & Age of child & 2.492 & $2.621 * * *$ & $2.599 * * *$ \\
\hline age: ${ }^{2}$ & Square of age & 9.155 & $9.783 * *$ & $9.614 * * *$ \\
\hline sex: & Sex of child & 0.547 & $0.521 *$ & 0.528 \\
\hline moc: & If the household has access to the medium or means of communication & 0.395 & $0.344 * * *$ & $0.339 * * *$ \\
\hline hh_size: & Size of the household & 6.245 & $7.292 * * *$ & $7.116^{* * *}$ \\
\hline
\end{tabular}

The probability of vaccine use is the dependent variable of our model. Other variables listed are the explanatory variables in the estimated probit model for upper caste, indigenous, and Dalit using the NLSS survey II and III for the 0-5 years age group

Source: calculated by authors, 2015

$* * *, * *, *$ Significantly different from upper caste at $\alpha=0.01,0.05$, and 0.1 levels, respectively 
Table 3 Unadjusted measure of vaccine utilization and difference between indigenous group and upper caste, and between Dalit and upper caste in Nepal

\begin{tabular}{ll}
\hline Unadjusted differences & $\begin{array}{l}\text { Percentage of children with } \\
\text { full utilization of vaccine }\end{array}$ \\
\hline Upper caste & $70.622 \%(1343$ of 1901) \\
Indigenous & $63.60 \%(1964$ of 3088) \\
Dalit & $64.17 \%(1051$ of 1638) \\
Sample total & 6627 \\
Difference in full utilization of vaccine & \\
Upper caste vs. indigenous & $7.022 \% * * *$ \\
Upper caste vs. Dalit & $6.452 \% * * *$ \\
\hline
\end{tabular}

Estimates are for children, aged 0-5 years, and are based on data from NLSS II and III survey data. The numbers in the parentheses are the number of individuals in the sample on which estimates are based

Source: calculated by authors, 2015

*** Significantly different from the estimate for upper caste at $\alpha=0.01$ level

Table 4 Adjusted measure of vaccine utilization and difference between indigenous and upper caste, and between Dalit and upper caste

\begin{tabular}{ll}
\hline Unadjusted differences & $\begin{array}{l}\text { Percentage of children with } \\
\text { full utilization of vaccine }\end{array}$ \\
\hline Upper caste & $70.622 \%(1343$ of 1901) \\
Indigenous & $62.575 \%(1932$ of 3088) \\
Dalit & $63.407 \%(1039$ of 1638) \\
Sample total & 6,627 \\
Difference in full utilization of vaccine & \\
Upper caste vs. indigenous & $8.047 \% * * *$ \\
Upper caste vs. Dalit & $7.215 \% * * *$ \\
\hline
\end{tabular}

Estimates are for children, aged 0-5 years, and are based on data from NLSS II and III survey data. The numbers in the parentheses are the number of individuals in the sample on which estimates are based

Source: calculated by authors, 2015

*** Significantly different from the estimate for upper caste at $\alpha=0.01$ level

components: (1) disparity attributable to the difference in coefficients across models for utilization; and (2) disparity attributable to difference in measurable characteristics of the groups after the indigenous and Dalit groups are assigned distribution of need-related variables comparable with those of the upper caste. The second component is further decomposed into parts due to difference in the distribution of explanatory variables such as natural logs of household income, parental education, distance to the nearest health center, urban versus rural location of the household, age of child, sex of child, access to the means of communication, size of the household, and the regional dummy.
For both indigenous and Dalit groups, the observed disparities in the utilization of vaccine are due more to the differences in the coefficient across the model, rather than differences in the measurable characteristics. Even though the differences in measurable characteristics such as parental education and household income explain the observed disparities in the utilization of vaccine is less, we decompose this component further into the determinants of vaccine demand function and reports the results at the second panel of Table 5 .

Much of the disparity in vaccine utilization between the indigenous and upper caste groups can be explained by geographic differences, factors such as urban versus rural location of household, region type (hilly or mountainous), and the distance to the nearest health facility. These differences suggest that future vaccination efforts should be mindful of how they extend into the further reaches of the country. A second key factor explaining the disparities would be socio-economic characteristics such as household income, parental education, and access to media. When we compare the decomposition results of the Dalit and upper caste groups, there is little difference from the differences between the indigenous and upper caste groups.

\section{Discussion}

In this section, we present five points that warrant further elaboration regarding the disparities in the utilization of vaccines that persist between the upper caste and the indigenous and Dalit groups.

First, the disparity between the indigenous and upper caste groups $(8.047 \%)$ is slightly higher than the differences between the Dalit and upper caste groups (7.215\%), and is significant to less than $1 \%$ (diff. $=0.832 \%$ ) significance level. This is largely because the distribution of indigenous households in Nepal is clustered in the mountains and hills and largely isolated from the settlements of the upper caste. That isolation inhibits the potential for peer and neighborhood effects regarding vaccine use. Compounding the isolation effect, indigenous parents have a lower level of education than upper caste parents, and may be less aware, through schooling, of the potential health benefits.

Second, for the indigenous and Dalit, the observed disparities in the utilization of vaccine is due more to the differences in the coefficient across the model, rather than to differences in the measurable characteristics. Thus, the disparity between groups might be due to the lack of understanding the health benefits of immunization among indigenous and Dalit parents.

Third, the disparity in vaccine utilization between the groups is driven by three major factors: (1) urban versus rural location of households, (2) regional location of 
Table 5 Nonlinear regression decomposition of Institute of Medicine (IOM) disparities in vaccine utilization between indigenous and upper caste and between Dalit and upper caste in Nepal

\begin{tabular}{lcr}
\hline & Indigenous group v. upper caste & Dalit v. upper caste \\
\hline Total disparity & 8.047 & 7.215 \\
Portion due to differences in coefficients across models & 9.637 & 9.602 \\
Portion due to differences in the measurable characteristics of groups & -1.590 & -2.383 \\
Contribution of specific characteristics to the total disparity & \\
Natural logarithm of household income & $0.522^{*}$ & $0.751^{*}$ \\
Parental education & $0.283^{*}$ & 0.060 \\
Distance to the nearest health facility & $-0.500^{*}$ & $-0.318^{*}$ \\
Urban versus rural location of household & $0.14^{*}$ & 0.034 \\
Age of child & -1.036 & $-1.821^{* *}$ \\
Square of age & -0.133 & 0.246 \\
Sex of child & -0.017 & -0.030 \\
Access to the medium or means of communication & -0.006 & -0.006 \\
Size of the household & 0.400 & 0.257 \\
Time & 0.172 & 0.030 \\
Region & $-1.415^{*}$ & $-1.587^{*}$ \\
\hline
\end{tabular}

(1) Estimates of the total disparity in row 1 are taken from the bottom panel of Table 4 . The total disparity equals the portion due to differences in coefficients across models for different subpopulations plus the portion due to differences in the measurable characteristics of subpopulations. (2) The portion of the total disparity due to differences in the measurable characteristics of subpopulation equals the sum of the contribution of specific characteristics. Thus, the entry of 0.522 on the row of "natural logarithm of household income" means that differences in the natural logarithm of household income between indigenous and upper caste contribute 0.522 towards the total disparity (of 8.047) in utilization of vaccines between these groups

Source: calculated by authors, 2015

$*, * *, * *$ Statistically different from 0 at $\alpha=0.10,0.05$, and 0.01 , respectively

household (e.g., mountains), and (3) the distance to the nearest health facility measured in terms of hours traveled. Broadly, this would indicate that vaccine services are limited in the furthest reaches of Nepal. However, this point is complicated when we look at Table 2, which indicates that the difference in reported travel times between indigenous and Dalit groups compared with the upper caste was significant at $1 \%$ significance level. We can explain this discrepancy when we note that a significantly higher number of upper caste group children live in urban areas compared to the mountain and hill regions. Thus, the more focused and enhanced access to vaccines in rural villages and mountain villages serving indigenous and Dalit groups may help explain this disparity.

Fourth, even though vaccines are available for no charge, the contribution of differences in household income to the disparity is significant in both cases. This might be due to the higher opportunity cost for indigenous and Dalit adults taking the time off work to take their children for vaccination. We conclude this because $54.66 \%$ of indigenous and $58.24 \%$ of Dalit are below poverty line compared to $41.24 \%$ of upper caste households below the poverty line.

Fifth, unlike household income, the difference in parental education is highly significant to explain the disparity between the indigenous and upper caste utilization of vaccines, but not for the disparity between Dalit and upper caste. We explicate this complication by looking at the size of land holdings, where Dalit are far behind both the upper caste and the indigenous group. Dalit households average land holding is 0.2135 hectares compared to the average upper caste holding if 0.284 hectares. Furthermore, Dalit land more often tends to be pakho land (unirrigated) compared to upper caste holdings which tend to be clustered along river banks and water sources. Thus, the absolute poverty among Dalits is higher compared to upper caste households. To make ends meet, many Dalit women are employed as wage laborers, oftentimes by upper caste families. Thus we suggest there may be a peer effect that informs Dalit while working for upper caste families. A secondary explanation takes into account that Dalit households tend to be groups within settlement patterns close to upper caste families, as many upper caste families rely on Dalit labor for household work. This suggests a neighborhood effect as well.

\section{Conclusion}

Significant disparity exists between indigenous and upper caste groups, and between Dalit and upper caste groups 
regarding the vaccination of children. A majority of the disparity in vaccine utilization is explained by the differences in geographic factors such as urban versus rural location of households, the regional location of households (e.g., mountainous), and the distance to the nearest health facility. Household income also explains a significant portion of disparity in both cases. Parental education significantly contributes to the disparity between indigenous and upper caste groups; however, the magnitude of contribution is very small. In case of the disparity between Dalit and upper caste, the contribution of parental education is insignificant and the magnitude of contribution is nominal.

As access to immunization services explains the majority of the disparity between Dalits and upper caste and between indigenous and upper caste, Nepal addresses this problem by reducing the differences in access, a problem that plagues many countries (Mahoney et al. 2007; Okeibunor et al. 2013). As poverty in Nepal is highly correlated with the quantity of the land holding and its productivity (Devkota et al. 2013), improvements in agricultural productivity could help alleviate poverty and, in doing so, perhaps enhance the utilization of immunization service. Both of those policies help to materialize the objective of $100 \%$ immunization in the country.

\section{References}

Abebaw D (2014) Socio-economic determinants of child immunization in rural Ethiopia. J Int Dev 26:1011-1023

Acharya LB, Cleland J (2000) Maternal and child health services in rural Nepal: does access or quality matter more? Health Policy Plan 15:223-229

Blinder AS (1973) Wage discrimination: reduced form and structural estimates. J Hum Resour 8:436-455

Borooah VK (2004) Gender bias among children in India in their diet and immunization against disease. Soc Sci Med 58:1719-1731

Centers for Disease Control (2011) Ten great public health achievements-worldwide 2001-2010. MMWR 60:814-818

Cook B, McGuire T, Miranda J (2007) Measuring trends in mental health care disparities 2002, 2004. Psychiatric Serv 58:1533-1540

Devkota S, Upadhyay M (2013) Agricultural productivity and poverty reduction in Nepal. Rev Dev Econ 17:732-746. doi:10.1111/ rode. 12062

Fairlie RW (1999) The absence of the African-American owned business analysis of the dynamics of self-employment. J Labor Econ 17:80-108

Fairlie RW (2005) An extension of the Blinder-Oaxaca decomposition technique to logit and probit models. J Econ Soc Meas 30:305-316
Gauri V, Khaleghian P (2002) Immunization in developing countries: its political and organizational determinants. World Dev 30:2109-2132

Grossman M (1972) On the concept of health capital and demand for health. J Polit Econ 80:223-255

Institute of Medicine (2002) Unequal treatment: confronting racial and ethnic disparities in health care. National Academy Press, Washington, DC

Kiros GE, White MJ (2004) Migration, community context, and child immunization in Ethiopia. Soc Sci Med 59:2603-2616

Kumar S, Dansereau EA, Murray CJL (2014) Does distance matter for institutional delivery in rural India? Appl Econ 46:4091-4103. doi:10.1080/00036846.2014.950836

Lee S (2005) Demand for immunization, prenatal selection and child survival: evidence from rural India. Rev Econ Househ 3:171-196

Mahoney RT, Krattiger A, Clemens JD, Curtiss R (2007) The introduction of new vaccines into developing countries: IV: global access strategies. Vaccine 25:4003-4011

McGuire T, Alegria M, Cook B et al (2006) Implementing the Institute of Medicine definition of disparities: an application to mental health care. Health Serv Res 41:1979-2005

Ministry of Health (MOH) [Nepal] (2007) Reaching every village: comprehensive multi-year plan of action 2007-2011. Department of Health Service, Child Health Division, Kathmandu

NEFIN nepal federation of indigenous nationalities (2015) http:// www.nefin.org.np/index.php. Accessed 25 Feb 2015

Oaxaca R (1973) Male-female wage differentials in urban labor markets. Int Econ Rev 14:693-709

Okeibunor JC, Akanmori BD, Balcha GM, Mihigo R, Vaz RM, Nshimirimana D (2013) Enhancing access to immunization services and exploiting the benefits of recent innovations in the African region. Vaccine 31:3772-3776

Pande RP (2003) Selective gender differences in childhood nutrition and immunization in rural India: the role of siblings. Demography 40:395-418

Pande RP, Yazbeck AS (2003) What is in a country average? wealth, gender, and regional inequalities in immunization in India. Soc Sci Med 57:2075-2088

Pandey, JP, MR Dhakal, S. Karki, P. Poudel, and MS Pradhan (2013) Maternal and child health in Nepal: the effects of caste, ethnicity, and regional identity: further analysis of the 2011 Nepal demographic and health survey, Nepal ministry of health and population, New ERA, and ICF International, Calverton

Wagstaff A, van Doorslaer E, Watanabea N (2003) On decomposing the causes of health sector inequalities with an application to malnutrition inequalities in Vietnam. J Econom 112:207-223

WHO (2013) WHO country cooperation strategy, 2013-2017: Nepal. World Health Organization, country office for Nepal. (C) World Health Organization 2013

WHO (2014) Fact sheet No. 114. World Health Organization, Geneva WHO, UNICEF (2005) Global immunization vision and strategy (GIVS) 2006-2015. WHO and UNICEF: Geneva and New York

World Bank (1993) World Development Report 1993: Investing in Heath. Oxford University Press, New York 